\title{
Pathogenicity of bloodstream and cerebrospinal fluid forms of Trypanosoma brucei rhodesiense in Swiss White Mice
}

\author{
Kariuki Ndung'u*, Maina Ngotho, Johnson Kinyua, John Kagira, Samuel Guya, Joseph Ndung'u and \\ Grace Murilla
}

Kenya Agricultural Research Institute - Trypanosomiasis Research Centre, PO Box 362, Kikuyu, Kenya

*Address for Correspondence: Kenya Agricultural Research Institute - Trypanosomiasis Research Centre, PO Box 362, Kikuyu, Kenya. Fax: +254-066-32397; Email: miringandungu@yahoo.com

\section{SUMMARY}

\begin{abstract}
Trypanosoma brucei rhodesiense (T.b.r.), the causative agent of the East African form of human African trypanosomiasis (HAT), is capable of crossing the blood brain barrier and invade the central nervous system (CNS). However, it is not clear whether bloodstream forms (BSF) of T.b.rhodesiense differ in biological characteristics from the cerebrospinal fluid (CSF) forms. The present study was carried out to compare the pathogenicity of CSF and BSF of T.b. rhodesiense parasites in Swiss white mice following intraperitoneal inoculation with $10^{6}$ trypanosomes. The parasites were tested for presence of the serum resistance associated (SRA) gene. Parasitaemia, body weight, packed cell volume (PCV) and survival of the mice was monitored daily until the experiment was terminated. Data was analyzed using general linear model. Both forms of parasite were positive for the SRA gene, and there was no significant difference in progression of parasitaemia, PCV values or survival of the mice. However, the weights of BSF infected mice initially dropped faster than those of CSF infected mice $(P<0.001)$. Key words: Trypanosoma brucei rhodesiense, bloodstream and CSF forms, pathogenicity, and mice.
\end{abstract}

[Afr J Health Sci. 2008; 15:34-41]

\section{Introduction}

Human African trypanosomosis (HAT) or sleeping sickness is caused by Trypanosoma brucei rhodesiense in east and southern Africa, and by T.b. gambiense in central and western Africa (1). The disease manifests in two sequential phases, an early stage when the parasites are demonstrated in haemolymphatic system and a second or late stage when parasites have invaded the central nervous system (CNS) (2). The mechanism through which the parasites cross the blood brain barrier (BBB) is not fully understood. It has been observed that in late stage disease, the BBB becomes compromised, allowing the trypanosome to pass into $\mathrm{CNS}$ more readily $[3,4]$. Previous studies reported that Trypanosoma b. brucei penetrates the CNS in areas such as the pituitary gland, where the
BBB is lacking [5]. Other workers have proposed that trypanosomes enter into CNS by a process of transcytosis through the vascular endothelium [6].

CSF is not a good medium for parasite growth and is thought to affect the phenotypic characteristics of the parasites [7,8]. Pentreath has suggested that as the disease progresses, changes occur in the cerebrospinal fluid (CSF), making it more 'hostile' to the trypanosome [8]. An increase in the level of whiteblood cells, IgM, and cytokines as well as changes in physiological state of CSF could be responsible for changes in the parasite phenotypic characteristics. Indeed, it has been argued that rapidly dividing trypanosomes will eventually produce a number of genetic mutants [9]. Changes in the CSF physiological environment 
may as a result select those parasites within the infra-population that can best survive in the altered environment [9]. Eventually, these parasites would have a different phenotype when compared to the bloodstream forms. Furthermore, when chronic $T$. brucei infections in mice are treated with suramin at $20 \mathrm{mg} / \mathrm{kg}$, relapsing trypanosomes from the brain exhibit a higher degree of human serum resistance than the original infection [10]. This could imply changes in the serum resistance associated (SRA) gene. It has also been observed that although T.b. rhodesiense parasites normally invade the CSF within 2 weeks after infection, parasites (following sub-curative therapy) can reside in the CSF for several months after relapses before invading the bloodstream. In the latter case, patients and animals rarely show any adverse clinical signs. However, the individuals later succumb to the meningoecephalitis caused by trypanosomes in the brain parenchyma (Ngotho J.M. personal communication).

It is not clear whether the trypanosomes in CNS are different in characteristics from the circulation forms. A World Health Organisation (WHO) scientific working group recommended that studies be carried out to determine whether there are differences between bloodstream and CSF trypanosomes [11]. This would improve the understanding of the pathogenesis of late stage sleeping sickness. The current study aimed at characterising two forms of trypanosomes isolated from a patient, based on their pathogenicity in the Swiss white mice.

\section{Materials and Methods}

Laboratory animals: Thirty-five Swiss white mice weighing 25-30g and obtained from Trypanosomiasis Research Centre (TRC) Animal Breeding Unit (Kenya) were used. Preinfection data on body weight and packed cell volume (PCV) was collected three times over a period of two weeks prior to inoculation with trypanosomes. The animals were de wormed by subcutaneous injection with ivermectin (Ivermectin ${ }^{\circledR}$ Anupco, England). They were maintained on a diet of commercial mice pellets (Mice pellets $\AA$, Unga Ltd, Nairobi, Kenya) and water ad libitum.
Trypanosomes and preparation of inoculum: Two T.b. rhodesiense forms (KETRI 3537 (BSF) and KETRI 3534 (CSF)) were isolated from an adult patient admitted at the former Kenya Trypanosomiasis Research Institute Alupe, sleeping sickness referral hospital in 1998. The parasites were initially passaged in Swiss white mice before being cryopreserved. During the experiment, the cryopreserved parasites were thawed and inoculated intraperitonially into two donor Swiss white mice for multiplication. At peak parasitaemia, the mice were euthanized by placing them in a chamber containing carbon dioxide $\left(\mathrm{CO}_{2}\right)$ and bled from the heart. The blood was collected into a tube containing EDTA and trypanosomes quantified using the improved Neubauer chamber. An inoculum dose of $1 \times 10^{6}$ trypanosomes was prepared using phosphate buffered saline containing glucose (PSG), $\mathrm{pH}$ 8.0 .

\section{Experimental design}

Mice: Adults male mice were infected by intraperitoneal injection with $1 \times 10^{6}$ trypanosomes and grouped as follows: (i) 15 infected with KETRI 3534, (ii) 15 infected with KETRI 3537, and (iii) 5 uninfected controls. The mice were monitored daily and the following parameters determined: prepatent period (PP), parasitaemia, PCV, weight and mortality. Packed cell volume (PCV) was determined as described by Cheesbrough [12] while parasitaemia was monitored using rapid matching technique [13]. All experimental procedures involving mice were reviewed and approved by the Animal Care and Use Committee (ACUC) of TRC.

Polymerase chain reaction (PCR): DNA was prepared by the standard phenol extraction and alcohol precipitation method [14]. Approximately 10ng of trypanosome DNA was used as a template for each PCR reaction. The SRA primers used in this study as well as the PCR were as described by Gibson [12].

Statistical analysis: The SAS version 8 statistical software was used to analyze the data, whereas the general linear model was used to compare the mean parasitaemia, $\mathrm{PCV}$ and 
weights of the different groups. Survival analysis was done using Log-rank tests.

\section{Results}

\section{SRA gene}

Both the BSF and CSF trypanosomes tested positive for the SRA gene as evidenced by the presence of an amplification revealed on agarose gel electrophoresis (bp) (Figure 1)

\section{Parasitaemia}

Figure 2 shows the parasitaemia patterns in mice infected with BSF and CSF trypanosomes. Mice infected with BSF parasites had a prepatent period (PP) of 4 days (range $=3-5$ days) and showed two waves of parasitaemia. The first peak of parasitaemia $\left(1 \times 10^{9}\right.$ trypanosomes $\left./ \mathrm{ml}\right)$ occurred between 5 and 8 days post-infection (dpi). This was followed by a fall in mean parasitaemia to $2.5 \times 10^{7}$ trypanosomes $/ \mathrm{ml}$ between 9 and $15 \mathrm{dpi}$, and a second peak (mean $4 \times 10^{8}$ trypanosomes $/ \mathrm{ml}$ ) between 16 and 25 dpi. The mice inoculated with CSF parasites had a PP of 4 days (range $=3-5$ days) and three waves of parasitaemia. The first (mean $1 \times 10^{9}$ trypanosomes $/ \mathrm{ml}$ ) occurred at $6 \mathrm{dpi}$, followed by a drop to a mean of $5 \times 10^{7}$ trypanosomes $/ \mathrm{ml}$ between 7 and $12 \mathrm{dpi}$, then a slight increase to a mean of $2.5 \times 10^{8}$ trypanosomes $/ \mathrm{ml}$, which remained at this level for approximately 14 days. A further increase (mean 1 x $10^{9}$ trypanosomes $/ \mathrm{ml}$ ) occurred between 29 and 34 dpi. Statistical analysis using general linear model showed no significant difference in these changes in parasitaemia between the BSF and CSF infected mice.

Figure 1. PCR amplification of the SRA gene from CSF and BSF of T.b. rhodesiense

Key

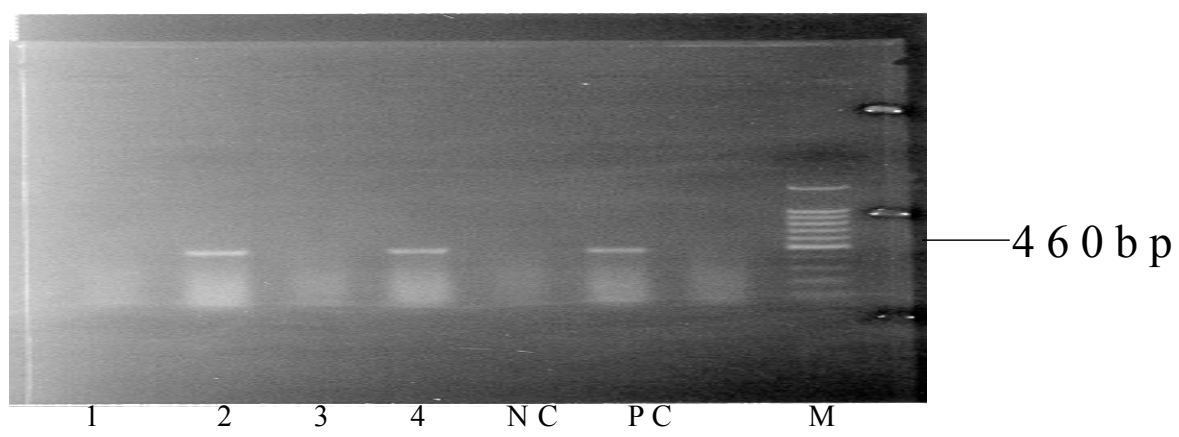

1) Negative control, 2) Test sample (CSF forms), 3) Negative control, 4) Test sample (Blood forms), NC-Negative control, PC- Positive control, M- markers

\section{Mice survival}

Figure 3 shows the survival rates of mice infected with BSF and CSF trypanosomes. The survival rate of BSF and CSF mice did not differ statistically between the 2 groups. However, the mortality of BSF infected mice was higher than that for the CSF infected mice. The mean survival period of BSF and CSF infected mice was 20.4 and 23 days, respectively.

\section{Packed cell volumes (PCV)}

The PCV values for both BSF and CSF infected mice were similar, but significantly lower than those of control non-infected mice (P $\left.=0.001, \mathrm{x}^{2}=17.09, \mathrm{df}=1\right)$. PCV values of both BSF and CSF trypanosomes infected mice dropped from $49 \%$ to $35 \%$ within $7 \mathrm{dpi}$. The values for both groups dropped further to $21 \%$ by $21 \mathrm{dpi}$. Interestingly, PCV values of CSF infected mice increased slightly from $21 \%$ to $26 \%$ between 22 and $34 \mathrm{dpi}$, but those for the BSF infected mice remained around $22 \%$ upto the end of experiment. There was no significant difference between the PCV changes in the mice infected with either the BSF or CSF forms of parasites. 
Fig 2. Parasitemia progression in mice infected with BSF and CSF forms of T.b. rhodesiense

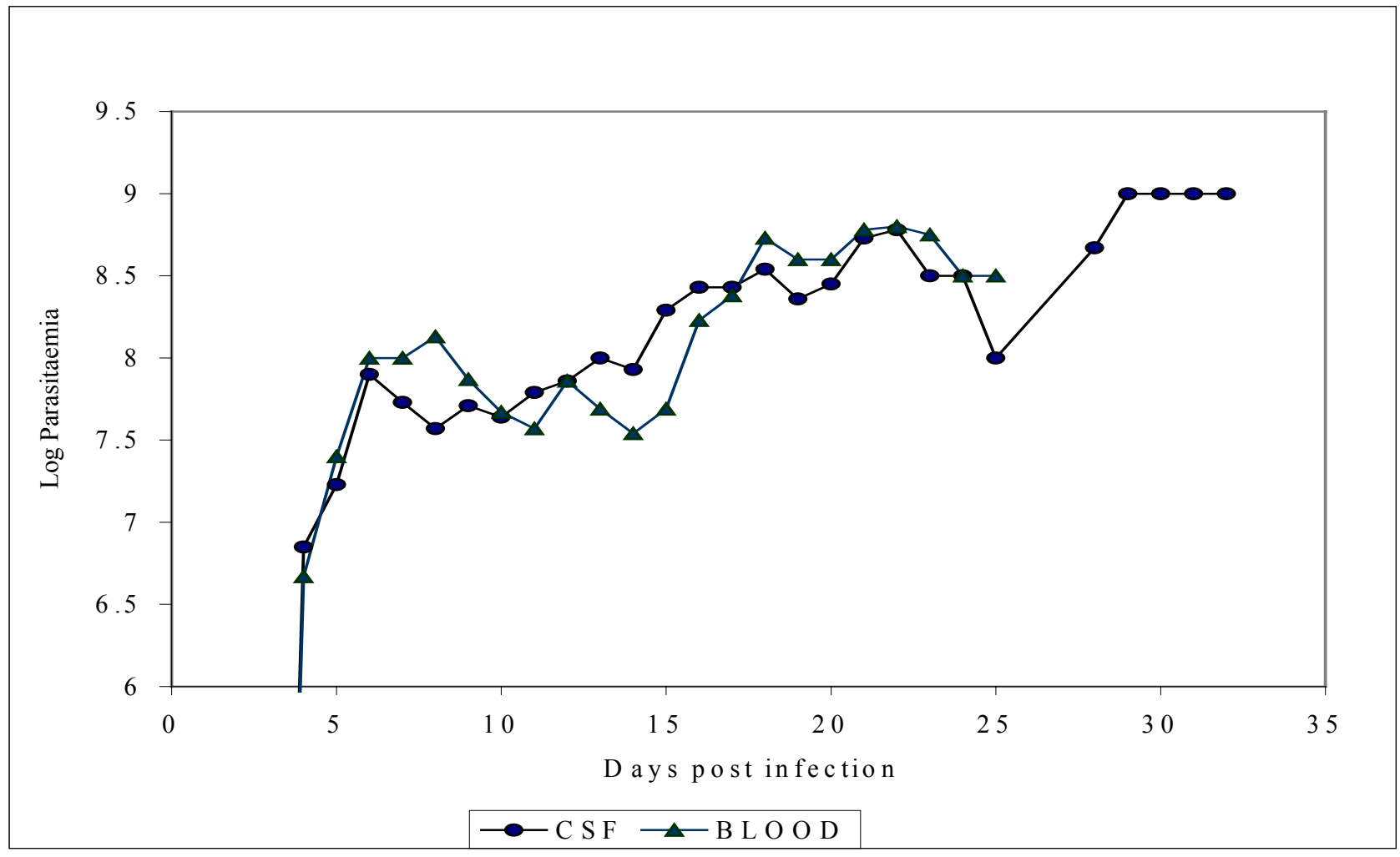

Fig 3. Survival rate of mice infected with BSF and CSF forms of T.b. rhodesiense

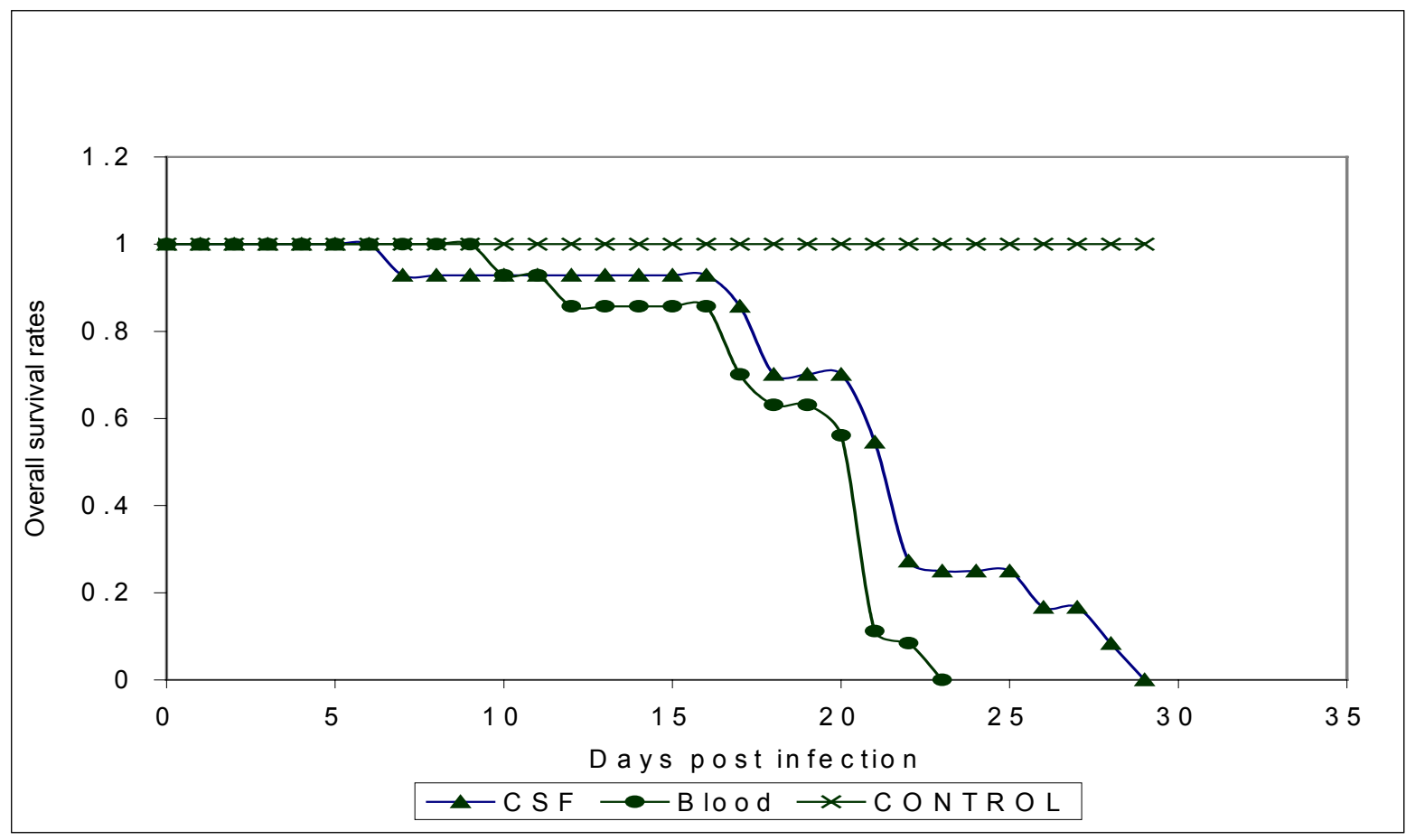




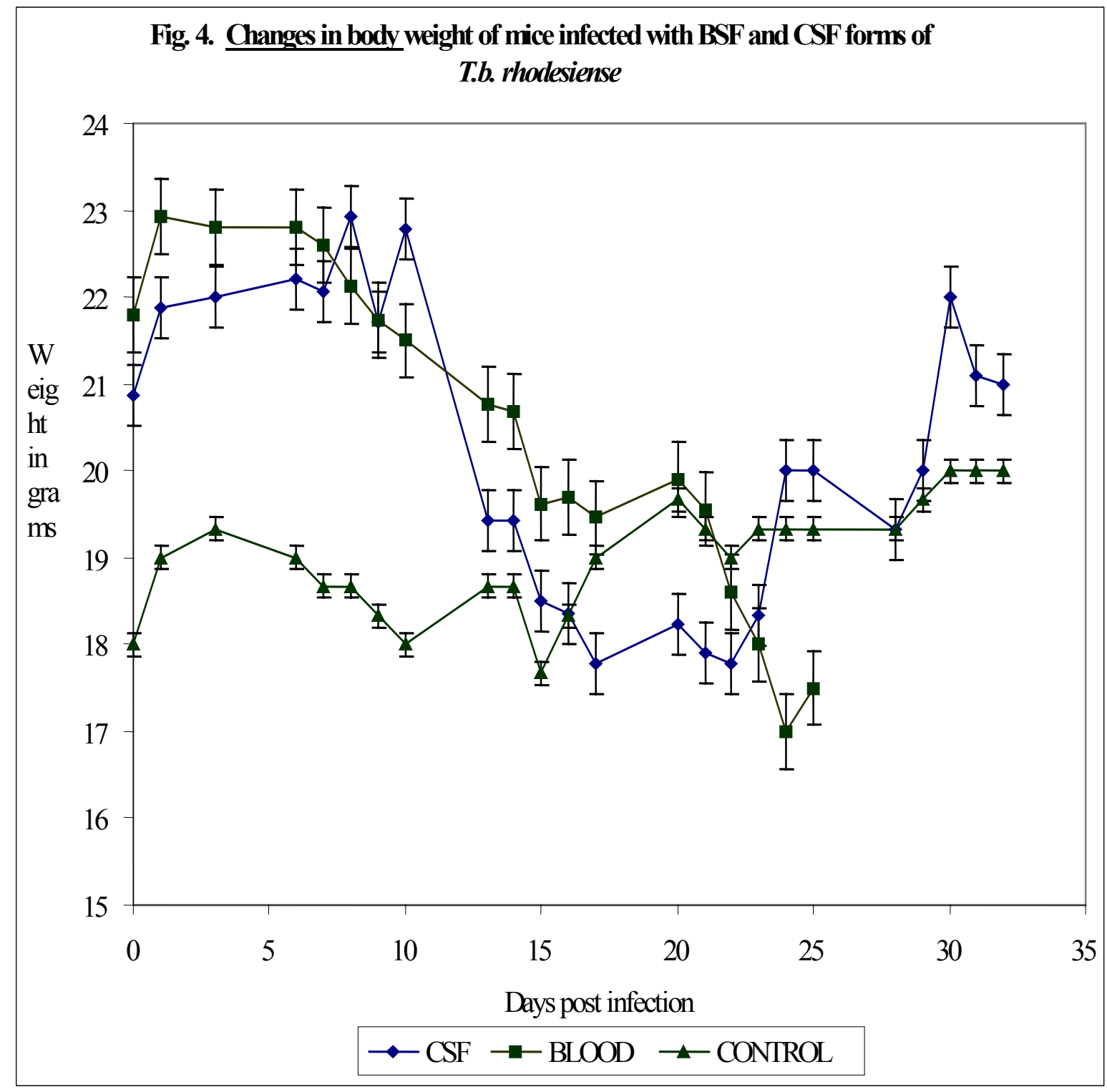

\section{Mice changes in body weight}

The changes in body weight varied between controls, BSF and CSF infected mice $(\mathrm{P}=0.001$, $\left.\mathrm{x}^{2}=58.24, \mathrm{df}=1\right)$. Whereas the mean body weight of BSF infected mice fell from $22 \pm 1.5 \mathrm{~g}$ to 19.5 $\pm 3 \mathrm{~g}$ by day 17 post infection, those of CSF infected mice fell from $21 \pm 1.8 \mathrm{~g}$ to $19 \pm 2.4 \mathrm{~g}$ within $13 \mathrm{dpi}$, and continued to fall gradually to $18 \pm 2 \mathrm{~g}$ by $20 \mathrm{dpi}$. A steady but gradual increase in body weight was observed between 23 and 30 dpi in CSF mice reaching $22 \pm 2.6$ by 30 dpi.

\section{Discussion}

The present study was carried out to characterise BSF and CSF forms of T.b. rhodesiense isolated from a sleeping sickness patient, based on their pathogenicity in Swiss white mice. The PCR results showed the presence of the SRA gene in both parasite groups, demonstrating the conserved nature of the SRA gene, even as the trypanosomes cross the BBB into the CSF. Previous studies have shown that the SRA gene is ubiquitous and conserved in T.b. rhodesiense $[14,15]$ and as such, has potential for the development of a highly specific diagnostic tool. Although BSF and CSF parasites had similar prepatent periods (of 4 days) in mice, with the first peak of parasitaemia occurring $6 \mathrm{dpi}$, the pattern of parasitaemia after that differed between the 2 groups. Mice infected with BSF 
parasites demonstrated fewer waves of parasitaemia than the mice infected with CSF forms. Expression of several waves of parasitaemia is an indicator of different variable antigen types (VATs) of trypanosomes to which immune response is elicited [16].

It can therefore be assumed that the antibodies raised against the CSF forms were capable of responding to the various VATs expressed, thus prolonging the life of the infected mice. Indeed, it was observed that the mortality rate of CSF infected mice was lower than in BSF infected mice. This concurs with results of earlier studies on relationships between parasitaemia and survival, that showed in cattle that the higher the parasitaemia, the greater the degree of pathogenicity [17]. It also turns out that the sex of the host also compounds the virulence of the trypanosomes, with females surviving longer than males $[18,19]$. Since the mice used in the present study were inbred Swiss white of the same sex, the difference in survival observed between BSF and CSF mice can largely be attributed to differences in virulence between the 2 parasites. It has also been reported that immunosuppresion associated with trypanosomosis contributes significantly to survival of infected hosts [20]. It will be interesting to compare the relative immunosuppresion that occurs in mice infected with BSF and CSF forms of trypanosomes.

The onset of anaemia in mice infected with the two groups of parasite was marked by a drop in PCV, coinciding with the first peak of parasitaemia, and continued to decline as the infection progressed, in agreement with observations from previous studies [21, 22]. The gradual rise in PCV from at 21 dpi suggests a recovery in erythropoiesis. Mice infected with the BSF and CSF forms had a fall in body weight drops between 13 and 15 dpi. This is not surprising, as similar observations have been reported in rats infected with T.b. brucei at 13dpi [23]. It has been suggested that the onset of weight loss could be associated with the initiation of second stage trypanosomosis in mice [24]. It is noted that body weight loss and anorexia are controlled by the hypothalamus, and as such the effect could be caused by entry of parasites into the brain [25].

\section{Conclusion}

Little is known about the differences in characteristics between BSF and CSF forms of T.b.rhodesiense isolated from the same patient. Results of the present study suggest conservation of the SRA gene in the CNS T.b rhodesiense trypanosomes. While no statistically significant differences were observed in parasitaemia, survival or PCV between mice infected with BSF and CSF forms, there was a statistically significant drop in weight in BSF infected mice, relative to the CSF mice. Considering that the CSF parasites are in an environment that may not be accessible to the vector and would only be accessible after relapses, it would be important to carry out a study to compare the transmissibility of the parasites before and after relapses.

\section{Acknowledgements}

This study received financial support from The Government of Kenya. The statistical analysis done by Dr. B. Bett and advice on experimental design by Mr. Ngae of KARI TRC as well as excellent technical assistance provided by members of Trypanosome Biology KARI-TRC (P. Gitonga, F. Njung'e, J. Ndichu, M. Andole, and $\mathrm{L}$. Mwende) is highly appreciated.

\section{References}

1. MacLean L, Chisi JE, Odiit M, Gibson WC, Ferris V, Picozzi K, and Sternberg JM . Severity of human african trypanosomiasis in East Africa is associated with geographic location, parasite genotype and host inflammatory cytokine response profile. Infection Immunology. $2004 ; 72: 7040$ 7044.

2. Peter GE. Kennedy. Human African trypanosomiasis of the CNS: current issues and challenges. Journal of Clinical Investigations. 2004; 113:496504

3. Masocha W, Robertson B, Rottenberg ME, Mhlanga J, Sorokin L and Kristensson K. Cerebral Vessel 
Laminins and IFN-gamma define Trypanosoma brucei brucei penetration of the blood-brain barrier. Journal of Clinical Investigations. 2004; 114: 689694.

4. Enanga B, Burchmore RJ, Stewart ML and Barrett MP. Sleeping sickness and the brain. Cell and Molecular Life Sciences. 2002; 59: 845- 858.

5. Schultzberg $M$, Ambatsis $M$, Samuelsson EB, Kristensson $\mathrm{K}$ and van Meirvenne N. Spread of Trypanosoma brucei to the nervous system: early attack on the circumventricular organs and sensory ganglia. Journal of Neuroscience Research. 1988; 21:56-61.

6. Mulenga C, Mhlanga, JD, Kristensson K and Robertson B. Trypanosoma brucei brucei crosses the blood-brain barrier while tight junction proteins are preserved in a rat chronic disease model. Neuropathology and Applied Neurobiology. 2001; 27: 77-85.

7. Pentreath VW, Owolabi AO and Doua F. Survival of $T$. brucei brucei in cerebrospinal fluid. Annals of Tropical Medicine and Parasitology. 1992; 86: 29-34.

8. Pentreath VW. Cytokines and the bloodbrain barrier in human and experimental African trypanosomiasis. In: Progress in Human African Trypanosomiasis, Sleeping Sickness. Dumas M, Bouteille B \& Buguet A, eds). Paris: Springer Verlag, 1999, 215p.

9. Seed JR and Sechelski JB. The individual host, a unique evolutionary island for rapidly dividing parasites; a theoretical approach. Journal of Parasitology. 1996; 82: 263-267.

10. Jennings FW, Urquhart GM. Induction of human serum-sensitive Trypanosoma brucei stabilates into human serumresistant "T.rhodesiense". Transactions of the Royal Society of Tropical Medicine and Hygiene. 1985; 79: 80-85.

11. World Health Organisation. Scientific working group on human African trypanosomosis, WHO, Geneva. 2001.

12. Cheesbrough, M. eds. District Laboratory Practice in Tropical countries, Volume 2. United Kingdom: University Cambridge Press, 2002 p 310-314.

13. Herbert WJ and Lumsden WH. Trypanosoma brucei: A rapid "matching" method for estimating the host parasitaemia. Experimental. Parasitology 1976; 40: 427-431.

14. Gibson W, Backhouse T, Griffiths A. The human serum resistance associated gene is ubiquitous and conserved in Trypanosoma brucei rhodesiense throughout East Africa. Infection Genetics and Evolution. 2002; 3: $207-$ 214

15. Njiru ZK, Ndung'u $K$, Matete $G$, Ndungu JM and Gibson WC. Detection of Trypanosoma brucei rhodesiense in animals from sleeping sickness foci in East Africa using the serum resistance associated (SRA) gene. Acta Tropica. 2004; 90: 249-254.

16. Bancroft, GJ and Askonas BA. Immunology of African trypanosomes in laboratory rodents. In I. Tizard (ed.), Immunology and pathogenesis of trypanosomiasis. Florida, 1985, p. 75101.

17. Cross GA. Identification, purification and properties of clone-specific glycoprotein antigens constituting the surface coat of Trypanosoma brucei. Parasitology. 1975; 71: 393-417

18. Seed JR \& Sechelski J. Growth of pleomorphic Trypanosoma brucei rhodesiense in irradiated inbred mice. Journal of Parasitology. 1988; 74:781789.

19. Greenblatt H C, Diggs CL and Rosentreich DL Trypanosoma brucei rhodesiense: Analysis of genetic control of resistance among mice. Infection and Immunity. 1984; 44: 107- 111.

20. Scott, JM, Pegram RG, Holmes PH, Pay TW, Knight PA, Jennings FW and Urquhart GM. Immunosuppresion in bovine trypanosomiasis: field studies using foot -and- mouth disease vaccine and clostridial vaccine. Tropical Animal Health and Production 1977; 9: 159165. 
21. Morrison WI, Murray M and McIntyre, WLM. Bovine trypanosomiasis. In: Diseases of cattle in the tropics: economic and zoonotic relevance, (M. Ristic and W.I.M. McIntyre, eds). The Hague: Nijhoff, 1981, p469-497.

22. Murray M. The anaemia of bovine African trypanosomiasis: an overview. In: Pathogenicity of Trypanosomes (Losos G and Chouinard A eds.). IDRC132e, 1979, p. 121-127.

23. Chevrier C, Canini F, Darsaud A, Cespulglio R, Buguet A and Bourdon L. Clinical assessment of the entry into neurological state in rat experimental African trypanosomiasis. Acta Tropica. 2005; 95:33-39.

24. Darsaud A, Bourdon L, Chevrier C, Keita M, Bouteille B, Queyroy A , Canini F, Cespuglio R, Dumas $M$ and Buguet A. Clinical follow-up in the rat experimental model of African trypanosomiasis. Experimental Biology and Medicine 2003; 228: 1355-1362.

25. Darsaud A, Chevrier C, Bourdon L, Dumas M, Burguet A and Bouteille B. Megazol combined with Suramin improves a new diagnosis index of the early meningo-encephalitic phase of experimental African trypanosomiasis. Tropical Medicine and International Health. 2004; 9: 83-91. 